NASZA DERMATOLOGIA Online OUR DERMATOLOGY Online

Source of Support: Nil

Competing Interests: None

\section{A STUDY ON TOPICAL CALCIUM DOBESILATE FOR THE TREATMENT OF LIMITED PLAQUE PSORIASIS}

\author{
Neerja Puri, Asha Puri \\ Department of Dermatology and Venereology, Punjab Health Systems Corporation, \\ Ferozepur, Punjab, India
}

Corresponding author: Dr. Neerja Puri neerjaashu@rediffmail.com

\begin{abstract}
Introduction: Topical dobesilate offers the potential for treatment of plaque psoriasis without atrophy or other local side effects associated with the use of topical corticosteroids. Fibroblast growth factor (FGF)-mediated pathways participate in many of the cellular events implicated in the pathogenesis of psoriasis. Thus, targeting FGF signals may be potentially therapeutic.

Aims: To study the efficacy of topical calcium dobesilate for the treatment of 50 patients of limited plaque psoriasis.

Methods: For the present study, fifty clinically diagnosed cases of psoriasis with limited number of plaques $(<5)$ were selected from the outpatient dermatology department. Lesions were treated with potassium dobesilate for a maximal period of 4 weeks. No other modality of treatment was used other than emollients and oral antihistaminics.

Results: The mean duration of disease in our study was $4.74+14.64$ years in our study. The mean reduction in PASI score with topical calcium dobesilate was statistically significant in our study $(\mathrm{p}>0.05)$.
\end{abstract}

Key words: psoriasis; PASI; treatment; diagnosis; calcium dobesilate; Fibroblast Growth Factor (FGF)

Cite this article:

Neerja Puri, Asha Puri: A study on topical calcium dobesilate for the treatment of limited plaque psoriasis. Our Dermatol Online. 2013 ; 4(3): 290-293.

\section{Introduction}

Psoriasis is a chronic recurrent papulosquamous disorder characterized by epidermal hyperplasia [1]. The management of psoriasis can be challenging. Although, there are many therapeutic modalities available but still there are no clear cut guidelines regarding the usage of different modalities depending on the severity of psoriasis [2]. Fibroblast growth factor (FGF)mediated pathways participate in many of the cellular events implicated in the pathogenesis of psoriasis [3]. Thus, targeting FGF signals may be potentially therapeutic in the treatment of psoriasis.

There is at present no cure for psoriasis, only suppressive therapy. The most common form for which most types of treatment are tested is plaque-type psoriasis, characterized by welldemarcated, erythematous, scaling plaques. It appears that several cell signaling events regulate the four major signs of this disease: keratinocyte hyperproliferation, low rate of keratinocyte apoptosis, angiogenesis and infiltration of inflammatory cells $[4,5]$. Targeting such signaling and transcriptional events with pharmaceutical intervention may help to reduce downstream cellular effects in psoriasis. The fibroblast growth factor (FGF) family is an ubiquitously expressed transmembrane signaling family that elicits receptor-mediated and survival $[6,7]$. The FGF ligands are single regulatory effects on cell growth, function, differentiation polypeptides consisting of 22 genetically distinct homologues and the FGF receptors (FGFRs) are transmembrane tyrosine kinases encoded by four homologous gene products, which form a complex with pericellular matrix heparan sulfates independent of the FGF ligand. Binding of FGF ligands to FGFR-heparan sulfate complexes activates the kinase activity and transmits regulatory signals to downstream signaling mediators or targets [8,9]. FGF stimulates a repertoire of canonical intracellular signaling pathways controlling many of the cellular events implicated in the pathogenesis of psoriasis [10-12]. We have shown previously that elevated plasma levels of FGF in psoriatic patients may be a useful predictor of clinical outcome and affect management [13,14]. Calcium dobesilate has been widely used for the treatment of diabetic retinopathy. Furthermore, it has been reported that this agent inhibits proliferation of vascular smooth muscle cell growth in serum containing, among other things, FGF. Recently, we have shown that dobesilate inhibits cell proliferation and promotes apoptosis in glioma cell cultures acting as an FGF inhibitor $[15,16]$. Based on the hypotheses about the activities of dobesilate, we assessed the effect of topical dobesilate in chronic plaque psoriasis.

\section{Aims}

1. To study the efficacy of topical calcium dobesilate for the treatment of 50 patients of limited plaque psoriasis.

2. To study any side effects of calcium dobesilate.

\section{Material and Methods}

For the present study, fifty clinically diagnosed cases of psoriasis with limited number of plaques $(<5)$ were selected from the outpatient dermatology department. 
All the patients were subjected to the routine investigations like haemoglobin assessment, complete blood count, Fasting blood sugar, erythrocyte sedimentation rate and urine complete examination, ASO titre and throat swab for culture along with specialized investigation including skin biopsy. A written informed consent was taken from all the patients before starting the study. Prior approval of hospital ethical committee was taken for the study. PASI score was calculated in all patients at the start of study and then every 2 weekly till the remission phase of the disease. The patients were evaluated at $0,2,4,6$ and 8 weeks and all patients were photographed. After 8 weeks, no treatment was given and the patients were asked to come for follow up every 4 weeks upto 24 weeks to see for any relapse.

Lesions were treated with potassium dobesilate [hydroquinone monosulfonic acid potassium salt (5 percent in a cream formulation, applied twice daily by the patient himself)] for a maximal period of 4 weeks. No other modality of treatment was used other than emollients and oral antihistaminics. Clinic visits during the treatment phase were at day 0 (baseline), day 7 and day 14. Assessments of efficacy and adverse events were made at each visit. Efficacy was evaluated based on the disease signs and symptoms in lesions. Disease signs include erythema, induration, desquamation and overall severity. Photographs of the lesions were taken at baseline and each visit until study completion. Compliance was judged to be good because of the patient's high motivation.

\section{Results}

The results were collected and the data was analyzed statistically.

\begin{tabular}{|l|l|l|}
\hline \multicolumn{1}{|c|}{ Duration of Psoriasis (in years) } & Number of Cases & Percentage \% \\
\hline Less than 5 years & 33 & 66 \\
\hline Between 5-10 years & 13 & 26 \\
\hline Between 11-15 years & 3 & 6 \\
\hline Between 16-20 years & 1 & 2 \\
\hline Total & 50 & 100 \\
\hline
\end{tabular}

Table I. Total duration of psoriasis

\begin{tabular}{|l|l|l|l|}
\hline \multicolumn{1}{|c|}{ SR no } & Triggering Factors in Psoriatics & Number of Cases & Percentage (\%) \\
\hline 1 & Stress & 24 & 48 \\
\hline 2 & Trauma & 10 & 20 \\
\hline 3 & Sore throat & 18 & 36 \\
\hline 4 & Alcoholism & 16 & 32 \\
\hline 5 & Drug intake & 18 & 36 \\
\hline 6 & Photo aggravation & 3 & 6 \\
\hline
\end{tabular}

Table II. Triggering factors in psoriasis

\begin{tabular}{|c|c|c|c|c|c|c|c|}
\hline \multirow{2}{*}{$\begin{array}{c}\text { SR no } \\
\text { Duration (in weeks) }\end{array}$} & \multicolumn{6}{|c|}{ Mean PASI Score Reduction } & \multirow[b]{2}{*}{ Significance } \\
\hline & $\begin{array}{l}0 \\
\text { weeks }\end{array}$ & $\begin{array}{l}2 \\
\text { weeks }\end{array}$ & $\begin{array}{l}4 \\
\text { weeks }\end{array}$ & $\begin{array}{l}6 \\
\text { weeks }\end{array}$ & $\begin{array}{l}8 \\
\text { weeks }\end{array}$ & $\begin{array}{l}\text { Mean \% age } \\
\text { reduction in PASI }\end{array}$ & \\
\hline Mean PASI score & 20 & 17.2 & 15.4 & 12.2 & 9.2 & PASI 50 & $\begin{array}{l}t=3.68 \\
p>0.05(S)\end{array}$ \\
\hline \multicolumn{8}{|c|}{ Table III. Reduction in PASI score with calcium dobesilate } \\
\hline
\end{tabular}

\section{Discussion}

In our study, maximum number of cases $(22 \%)$ were in the age group of 51-60 years. It was followed by $20 \%$ in the age group of $31-40$ years, $18 \%$ in the age group $21-30$ years, $16 \%$ in the age group $41-50$ years, $16 \%$ in the age group $11-20$ years, $12 \%$ in the age group $0-10$ years and $8 \%$ of the cases were above 60 years of age. Mean age of psoriasis in our patients was $38.46+3.287$ out of 50 psoriatics, $31(62 \%)$ were males, while $19(38 \%)$ were females. Male to female ratio was 1.63: 1 . The duration of the psoriasis was less than 5 years was seen in $66 \%$ of cases, between 5 and 10 years in $26 \%$ of cases, between 11 and 15 years in $6 \%$ of cases, between 16 and 20 years in $2 \%$ of cases. The mean duration of disease in our study was $4.74+14.64$ in our study. The mean reduction in PASI score (Fig. 1, 1a) after eight weeks of treatment with topical calcium dobesilate was statistically significant in our study ( $\mathrm{p}>$ $0.05)$. PASI 50 is defined as a reduction from baseline PASI score of $>50 \%$. These days, PASI 50 (or a reduction in PASI score of $50 \%$ ) is used to assess severity of psoriasis.

Although psoriasis is rarely life threatening, it can cause significant morbidity, social embarrassment and financial cost and disruption in patients life; while patients with extensive and severe disease may require systemic therapy, less severe psoriasis is typically treated with topical medications [17]. After four weeks of treatment, the patient had almost completed clinical resolution of the lesions with no recurrence after two months of treatment withdrawal. No adverse events were observed. Psoriasis varies widely in its clinical expression, from a single fingernail pit to widespread disfiguring skin lesions and disabling arthritis. 


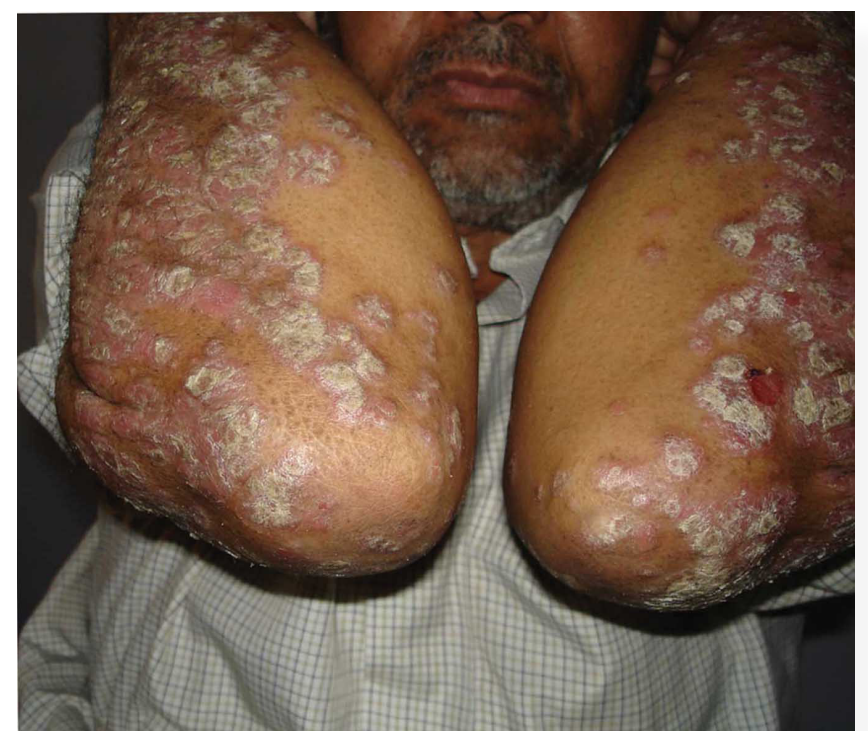

Figure 1. Psoriasis vulgaris before treatment

\section{Discussion}

The primary goal of therapy is to maintain control of the illness so as to avoid disruption of the patient's quality of life, as cure is seldom achieved. Treatment options include systemic agents, topical therapies, and phototherapies. Many of the currently available systemic treatments and phototherapies are associated with unacceptable toxicity or side effects. The most common side effects with topical corticosteroids include skin atrophy, irreversible striae, telangectasia, perioral dermatitis, glaucoma and acne $[18,19]$. These adverse reactions are more common with use in facial and intertriginous areas. Facial and intertriginous skin is more susceptible to corticosteroid- induced atrophy because of higher percutaneous absorption in these areas. In addition, continued corticosteroid therapy is thought to result in tachyphylaxis, a condition in which stronger formulations of the medication are required to maintain the therapeutic benefit. There may also be a recurrence of the disease if corticosteroid therapy is abruptly withdrawn. A derivate of vitamin $\mathrm{D}$, calcipotriene, another topical therapeutic option for psoriasis, is associated with local skin irritation, particularly in intertriginous areas, often requiring adaptation of the therapeutic regime such as dilution. Thus, from a clinical perspective, a nonatrophogenic, nonirritating topical treatment would address a significant patient need. Potassium dobesilate cream $5 \%$ is effective for the treatment of chronictype plaque psoriasis [20,21]. Calcium dobesilate acts on the the endothelial layer and basement of the blood capillaries. It reduces capillary hyperpermeability by increasing the activity of endothelial nitric oxide synthetase in vascular endothelial cells, leading to an increase in nitric oxide synthesis. This relaxes the vessels, closes the gaps and decreases the capillary hyperpermeability. Substantial and rapid clinical improvement was demonstrated in the assessment of lesions, resulting in improvements in erythema, desquamation, induration and overall severity. Recognition of psoriasis as a T-cell mediated immune disease has led to the development of various therapeutic approaches directed against $\mathrm{T}$ cell and $\mathrm{T}$-cell processes such as activation, trafficking and cytokine release. T cells synthesize FGF and have FGF receptors, suggesting that this growth factor may also be involved in T cell activation within psoriasis sites [22]. Thus, in addition to its antiproliferative and proapoptotic functions, dobesilate may also be effective by abolishing $\mathrm{T}$ cell activities in psoriasis [23].

\section{Conclusions}

Although, calcium dobesilate is a very useful and FDA

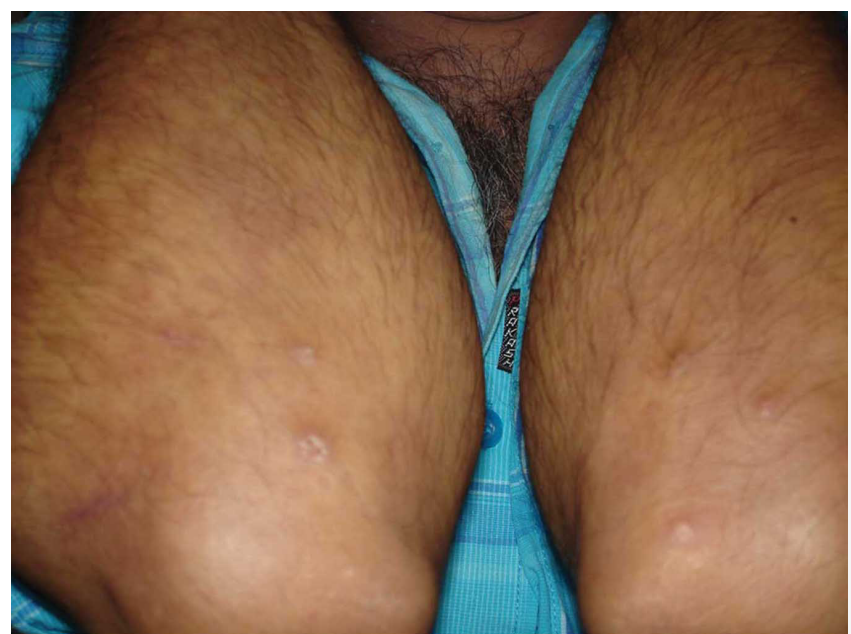

Figure 1a. Psoriasis vulgaris after treatment

approved drug for the treatment of plaque psoriasis, still large-scale studies with long-term follow-up are necessary for evaluating the final efficacy of this drug.

\section{REFERENCES}

1. Krueger GG, Bergstresser PR, Lowe NJ, Voorhess JJ, Weinstein GD: Psoriasis. J Am Acad Dermatol. 1984;11:937-47.

2. Camp RDR. Psoriasis. In: Champion RH, Burton JL, Burns DA, Breathnach SM, editors. Textbook of dermatology. 6th ed., Vol. 3. Oxford: Blackwell Scientific Publications; 1998. p.1589-1649.

3. Lebwohl M, Abel E, Zanolli M, Koo J, Drake L: Topical therapy for psoriasis. Int J Dermatol. 1995;34:673-84.

4. Linden KG, Weinstein GD: Psoriasis: current perspectives with an emphasis on treatment. Am J Med. 1999;107:595-605.

5. Nickoloff BJ: The cytokine network in psoriasis. Arch Dermatol. 1991;127:871-84.

6. Tan Y, Low KG, Boccia C, Grossman J, Comb MJ: Fibroblast growth factor and cyclic AMP (cAMP) synergistically activate gene expression at a cAMP response element. Mol Cell Biol. 1994; 17:7546-56.

7. Bushdid PB, Brantley DM, Yull FE, Blaeuer GL, Hoffman LH, Niswander $\mathrm{L}$ et al: Inhibition of NF-kB activity results in disruption of the apical ectodermal ridge and aberrant limb morphogenesis. Nature. 1998;392:615-8.

8. Geller SF, Lewis GP, Fisher SK: FGFR1, signaling, and AP-1 expression after retinal detachment: reactive Muller and RPE cells. Invest Ophthalmol Vis Sci. 2001;42:35-7.

9. Byrd VM, Ballard DW, Miller GG, Thomas JW: Fibroblast growth factor-1 (FGF-1) enhances IL-2 production and nuclear translocation of NF-kB in FGF receptor-bearing Jurkat $\mathrm{T}$ cells. J Inmunol. 1999;162:5853-9.

10. Reilly JF, Maher PA: Importinb-mediated nuclear import fibroblast growth factor receptor: role in cell proliferation. J Cell Biol. 2001;152:1307-12.

11. Schlessinger J: Common and distinct elements in cellular signaling via EGF and FGF receptors. Science. 2004;306:1506-7.

12. Robert C, Kupper TS: Inflammatory skin diseases, T cells and inmune surveillance. New Engl J Med. 1999;341:1817-28.

13. Miracco C, Pellegrino M, Flori M, Vatti R, Materno M, Andreassi L: Cyclin D1, B and A expression and cell turnover in psoriatic skin lesions before and after cyclosporin treatment. Br J Dermatol. 2000;143:950-6. 
15. Berthet Ph, Farine JC, Borras JP: Calcium dobesilate (Doxium“). Pharmacological profile related to its use in diabetic retinopathy. Int J Clin Pract. 1999;53:631-6.

16. Parés-Herbute N, Fliche E, Monnier L: Involvement of nitric oxide in the inhibition of aortic smooth muscle cell proliferation by calcium dobesilate. Int J Angiol. 1999;8:5-10.

17. Ashcroft DM, Li Wan PA, Griffiths CE: Therapeutic strategies for psoriasis. J Clin Pharm Ther. 2000;25:1-10.

18. Walsh P, Aeling JL, Huff L, Weston WL: Hypothalamus-pituitaryadrenal axis suppression by superpotent topical steroids. J Am Acad Dermatol. 1993;29:501-3.

19. Mills CM, Marks R: Side effects of topical glucocorticoids. Curr Probl Dermatol. 1993;21:122-31.

20. Piller NB: Assessment of the anti-inflammatory action of calcium dobesilate. Eur J Med Res. 1990;40:698-700.
21. Blotnick S, Peoples GE, Freeman MR, Eberlein TJ, Klagsbrun M: T Lymphocytes synthesize and export heparin-binding epidermal growth factor-like growth factor and basic fibroblast growth factor: mitogens forn vascular cells and fibroblasts: differential production and release CD4+ and CD8+ cells. Proc Natl Acad Sci. 1994;91:28904 .

22. Zhao X-M, Byrd VM, McKeehnan WL, Reich MB, Miller GG; Thomas JM: Costimulation of human CD4+ T cells by fibroblast growth factor-1 (acidic fibroblast growth factor). J Immunol. 1995; 155:3904-11.

23. Byrd V, Zhao X-M, McKeehnan WL, Miller GG, Thomas JW: Expression and functional expansion of fibroblast growth factor receptor $\mathrm{T}$ cells in rheumatoid synovium and peripheral blood patients with rheumatoid arthritis. Arthritis Rheum. 1996;39:914-22.

Copyright by Neerja Puri, et al. This is an open access article distributed under the terms of the Creative Commons Attribution License, which permits unrestricted use, distribution, and reproduction in any medium, provided the original author and source are credited. 